\title{
3D Digital scanning imaging for cultural heritage preservation: The case study of Greek Churches in Transylvania
}

\section{Bogdan Eugen Anagnastopol}

Babes Bolyai University,Cluj-Napoca- Romania

\begin{abstract}
Starting the late $18^{\text {th }}$ century, following the Joseph the II edict, in Transylvania Greek Churches were built to serve the needs of the orthodox community. Besides the historical importance of the Greek Churches who were built with support by the Greek merchants, who lived in Transylvania for trading purposes, the architectural and artistic value of these churches, in European context, its highly important for Transylvania spiritual and cultural heritage. Using the 3D scanning technology, we are able to analyze and preserve the material heritage in digital format, as a interdisciplinary collaboration creating a hybrid research study. In close connection with the digital technologies inventions and methods, humanities studies are now integrating digital technologies to develop the research methods and to get more answers for the research question. As a result of the integration of digital technologies in the Humanities studies, new disciplines like Digital Humanities emerged. The study aims to present the Greek Churches from Transylvania built in late $18^{\text {th }}$ century, from digital humanities point of view, analyzing the 3D digital scanning images and to present the advantages in cultural heritage preservation.
\end{abstract}

Keywords: Cultural Preservation; Digital heritage; Digital Humanities; Ethnology; Hybrid

Discipline 